Tạp chí Khoa học và Công nghệ biển T11 (2011). Số 3. Tr 57 - 69

\title{
THÀNH PHẦN LOÀI VÀ PHÂN BỐ CỦA RONG BIỂN QUẦN ĐẢO LÝ SƠN, QUẢNG NGÃI
}

\author{
ĐÀM ĐỨC TIẾN, LÊ VĂN SƠN \\ Viện Tài nguyên và Môi trường biển \\ VŨ THANH CA \\ Viện Nghiên cứu Quản lý biển và hải đảo
}

\begin{abstract}
Tóm tắt. Lý Son là một quần đảo (gồm hai đảo là Lý Sơn và An Bình) thuộc tỉnh Quảng Ngãi. Cho đến nay, đã có một số công trình nghiên cứu về rong biển đảo Lý Sơn. Đây là kết quả của hai chuyến khảo sát vào tháng $11-2009$ và tháng 5 - 2010 tại quần đảo Lý Sơn trên 8 mặt cắt (4 mặt cắt tại đảo Lý Son và 4 mặt cắt tại đảo An Bình) trong khuôn khổ đề tài: "Điều tra đánh giá hiện trạng các hệ sinh thái, xây dựng luận cú khoa học đề xuất dư án khu bảo tồn thiên nhiên biển phuc vu du lịch ở vùng biển ven bờ huyện Lý Sơn".

Kết quả nghiên cứu về rong biển đã phát hiện được 133 loài rong biển tại vùng biển quần đảo Lý Sơn. Trong đó, rong Lam (Cyanophyta) có 13 loài, rong Đỏ (Rhodophyta) có 71 loài, rong Nâu (Phaeophyta) có 22 loài và rong Luc (Chlorophyta) có 27 loài. Số luợng loài tại các mặt cắt I đến VIII dao động trong khoảng 54 loài/mặt cắt (mặt cắt VIII) đến 71 loài (mặt cắt IV) và trung bình là 63 loài/mặt cắt. Hệ số tuoong đồng Sorenson tại các mặt cắt dao động tì̀ 0,46 (giũa mặt cắt II và VII, giữa II và VIII) đến 0,64 (giũa mặt cắt IV và V) và trung bình là 0,56. Về phân bố sâu, trong số 133 loài rong biển đã phát hiện được, có tới 119 luợt loài phân bố ở vùng triều và 99 luợt loài phân bố ở vùng duới triều, trong đó có 83 loài phân bố ở cả vùng triều và duới triều. Phần lớn các loài phân bố trên dải tù̀ vùng triều giữa xuống đến độ sâu khoảng $5 \mathrm{~m}$ so với Om hải đồ và khu hệ rong biển vùng quần đảo Lý Sơn mang tính nhiệt đới với chi số $C=4,5$.
\end{abstract}

\section{MỞ ĐẦU}

Lý Sơn là quần đảo (gồm hai đảo là Lý Sơn và An Bình) thuộc tỉnh Quảng Ngãi, miền Trung nước ta. Đây là một trong những vùng đã được đưa vào kế hoạch thiết lập khu bảo tồn biển từ năm 1998 và là một trong 16 khu bảo tồn biển (KBTB) đã được Chính phủ công nhận chính thức năm 2010.

Do Lý Sơn nằm trong vùng biển có khí hậu nhiệt đới, tương đối xa bờ, ít chịu ảnh hưởng của nguồn nước ngọt từ lục địa,...nên có điều kiện rất thuận lợi cho sự tồn tại và 
phát triển của nhiều nhóm sinh vật biển, trong đó có rong biển. Lý Sơn cũng là vùng biển có cả hai hệ sinh thái nhiệt đới biển điển hình là san hô và cỏ biển.

Cho đến nay, đã có một số công trình nghiên cứu về rong biển quần đảo Lý Sơn (chủ yếu ở đảo Lý Sơn) và chưa có ở đảo An Bình $[3,5]$. Việc nghiên cứu đầy đủ về thành phần loài và phân bố của rong biển quần đảo Lý Sơn góp thêm nguồn tài liệu khi thiết lập KBTB và lập phát triển kinh tế biển-đảo, và để khai thác bền vững nguồn lợi.

Bài báo này trình bày kết quả điều tra rong biển tại quần đảo Lý Sơn trong khuôn khổ đề tài: "Điều tra đánh giá hiện trạng các hệ sinh thái, xây dưng luận cứ khoa học đề xuất dụ án KBTB phục vu du lịch ở vùng biển ven bờ huyện Lý Son".

\section{TÀI LIỆU VÀ PHƯƠNG PHÁP NGHIÊN CƯU}

\section{Tài liệu}

Bài báo tổng hợp kết quả của hai chuyến khảo sát vào mùa mưa (tháng 11 - 12 năm 2009) và mùa khô (tháng 5 năm 2010), tại 8 mặt cắt chính, trong đó 4 mặt cắt tại đảo Lý Sơn và 4 mặt cắt tại đảo An Bình (hình 1 ). Ngoài ra, các tác giả còn tham khảo một số công trình nghiên cứu về rong biển tại đảo Lý Sơn [3, 5].

\section{Phương pháp}

Khảo sát rong vùng triều dựa vào Quy phạm tạm thời điều tra tổng hợp biển (phần Rong biển) của Uỷ ban Khoa học và Kỹ thuật Nhà nước ban hành năm 1981 [6]. Khảo sát rong vùng dưới triều dựa vào tài liệu hướng dẫn của English, Wilkinson\&Baker (1997) [7] bằng thiết bị lặn SCUBA, máy chụp ảnh dưới nước hiệu OLYMPUS kỹ thuật số.

Mẫu rong tươi sau khi thu được ngâm trong dung dịch Formol 5\%, còn mẫu khô (tiêu bản) được đặt trên giấy Croki sau đó ép trong giấy thấm.

Mẫu vật được phân tích trong phòng thí nghiệm của Phòng Sinh thái và Tài nguyên thực vật biển, Viện Tài nguyên và Môi trường biển. Việc định loại chủ yếu dựa vào các tiêu chuẩn về hình thái ngoài và cấu tạo trong. Lát cắt tiêu bản được soi trên kính hiển vi Leica. Việc phân loại rong biển tuân theo nguyên tắc chung phân loại thực vật. Tài liệu định loại căn cứ vào các công trình của Nguyễn Hữu Đại [2], Phạm Hoàng Hộ [4], Nguyễn Hữu Dinh và nnk [1] và những tài liệu về định loại rong biển khác.

Nghiên cứu phân bố thẳng đứng của rong biển dựa vào nguyên tắc phân chia vùng triều của Feldmann (1937) [6], Stephenson (1945) [6] và Phạm Hoàng Hộ (1962) [4], bao gồm các vùng: vùng trên triều, vùng triều (triều cao, triều giữa và triều thấp) và vùng dưới triều. Phân bố mặt rộng trong không gian của rong biển. Để nghiên cứu sự phân bố địa lý 
của rong biển, chúng tôi đã sử dụng chỉ số tương đồng Sorenson $(S)$ với $S=2 C /(A+B)$. Trong đó: $\mathrm{A}$ là số loài tại điểm $\mathrm{A} ; \mathrm{B}$ là số loài tại điểm $\mathrm{B} ; \mathrm{C}$ là số loài chung giữa hai điểm $\mathrm{A}$ và $\mathrm{B}$. Các số liệu này được đưa vào các hàm của Excel để tính toán cho ra kết quả cuối cùng.

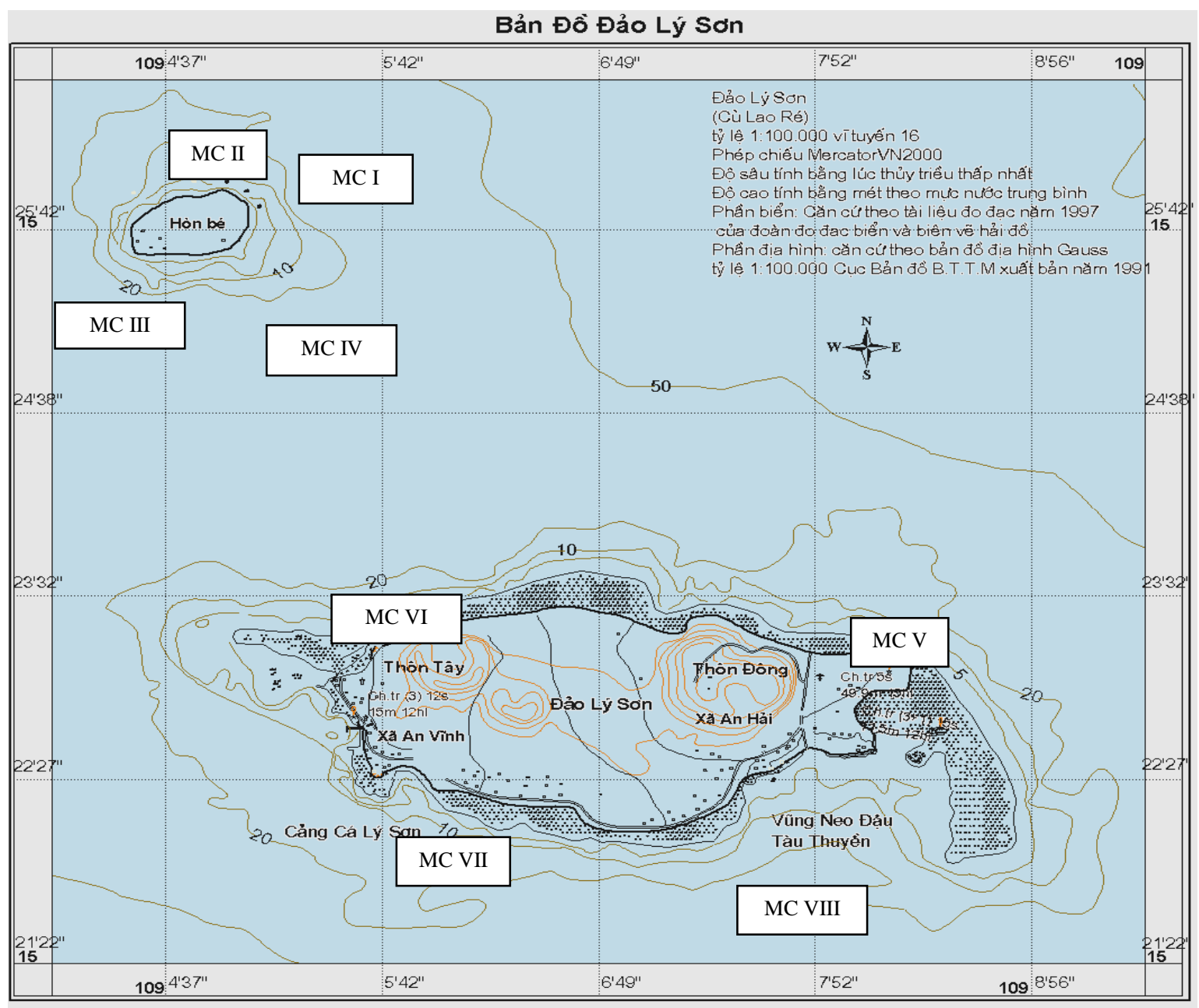

Hình 1: Sơ đồ khảo sát rong biển tại quần đảo Lý Sơn

Việc nghiên cứu khu hệ rong biển quần đảo Lý Sơn dựa theo phương pháp Cheney. Phương pháp này căn cứ vào tỷ số giữa tổng số loài rong Đỏ và rong Lục chia cho rong Nâu. Nếu tỷ số này nhỏ hơn 3 , khu hệ mang tính ôn đới, lớn hơn 3 là nhiệt đới và nằm trong khoảng giữa 3 và 6 là hỗn hợp [8]. 


\section{KẾT QUẢ NGHIÊN CÚU}

\subsection{Thành phần loài}

Qua việc phân tích các mẫu rong biển thu được trong hai chuyến thực địa mùa mưa (2009), mùa khô (2010) và tham khảo các nguồn tài liệu đã được công bố, chúng tôi đã xác định được 133 loài rong biển. Trong đó, rong Lam (Cyanophyta) có 13 loài, chiếm $9,8 \%$ tổng số loài; 71 loài rong Đỏ (Rhodophyta), chiếm 53,4\%; 22 loài rong Nâu (Phaeophyta), 16,6\%) và 27 loài rong Lục (Chlorophyta), 20,3\% (bảng 1).

Bảng 1: Thành phần loài và phân bố của rong biển quần đảo Lý Sơn

\begin{tabular}{|c|c|c|c|c|c|c|c|c|c|c|c|}
\hline \multirow[t]{3}{*}{ TT } & \multirow[t]{2}{*}{ Tên taxon } & \multicolumn{8}{|c|}{ Phân bố rộng } & \multicolumn{2}{|c|}{$\begin{array}{c}\text { Phân bố } \\
\text { sâu }\end{array}$} \\
\hline & & 1 & 2 & 3 & 4 & 5 & 6 & 7 & 8 & 10 & 11 \\
\hline & Cyanophyta & & & & & & & & & & \\
\hline 1 & $\begin{array}{l}\text { Microcoleus chthonoplaste } \\
\text { Thur. et Gom }\end{array}$ & + & + & + & + & & + & + & + & + & \\
\hline 2 & $\begin{array}{l}\text { Symploca hydnoides Kuetz. } \\
\text { ex Gom. }\end{array}$ & + & + & + & + & & + & + & + & + & \\
\hline 3 & $\begin{array}{l}\text { Lyngbya aestuarii Liebm. } \\
\text { ex Gom. }\end{array}$ & + & & + & & & + & & + & + & \\
\hline 4 & L. confervoides C. Ag. & & & & & & + & & & + & \\
\hline 5 & $\begin{array}{l}\text { Oscillatoria simplicissima } \\
\text { Gom. }\end{array}$ & + & & & & + & & + & + & + & \\
\hline 6 & $\begin{array}{l}\text { O. miniata (Zanard.) } \\
\text { Hauck }\end{array}$ & + & & & & + & & + & & + & \\
\hline 7 & Phormidium corium Gom. & + & & + & + & + & & + & & + & \\
\hline 8 & Calothrix pilosa Harv. & + & + & + & + & + & & + & & + & \\
\hline 9 & C. crustacea Thuret & & + & + & & + & & & & + & \\
\hline 10 & C. parietina Thuret & & + & + & & + & & & & + & \\
\hline 11 & $\begin{array}{l}\text { Hormothamnion solutum } \\
\text { Born. et Fl. }\end{array}$ & & & + & + & + & + & + & + & + & + \\
\hline 12 & $\begin{array}{l}\text { Brachytrichia maculans } \\
\text { Gom. }\end{array}$ & + & + & + & + & + & + & + & + & + & \\
\hline
\end{tabular}




\begin{tabular}{|c|c|c|c|c|c|c|c|c|c|c|c|}
\hline 13 & $\begin{array}{l}\text { B. quoyi (C. Ag.) Born. Et } \\
\text { Fl. }\end{array}$ & + & + & & + & + & + & + & + & + & \\
\hline & Rhodophyta & & & & & & & & & & \\
\hline 14 & $\begin{array}{l}\text { Chroodactylon ornatum } \\
\text { (C.Ag.) Basson }\end{array}$ & + & & + & & + & & & & + & \\
\hline 15 & $\begin{array}{l}\text { Stylonema alsidii (Zan.) } \\
\text { Drew }\end{array}$ & + & & + & & & & & & + & + \\
\hline 16 & $\begin{array}{l}\text { Erythrotrichia carnea } \\
\text { (Dillwyn) J.Ag }\end{array}$ & & + & & & & & & & + & + \\
\hline 17 & $\begin{array}{l}\text { Acrochaetium gracile } \\
\text { Boerg. }\end{array}$ & & + & & & + & + & & & + & + \\
\hline 18 & A. subseriatum Boerg. & & + & & & & & & & + & + \\
\hline 19 & $\begin{array}{l}\text { Actinotrichia fragilis } \\
\text { (Forsk.) Boerg. }\end{array}$ & + & + & & & & & & & + & + \\
\hline 20 & $\begin{array}{l}\text { G. obtusata (Ellis et } \\
\text { Solander) Lamx. }\end{array}$ & & & + & & & & & & + & + \\
\hline 21 & Scinaria boergesenii Tseng & + & & & & & & & & + & + \\
\hline 22 & $\begin{array}{l}\text { Ganonema farinosa } \\
\text { (Lamx.) Fan et Wang }\end{array}$ & & + & & & & & & & + & + \\
\hline 23 & Liagora divaricata Tseng & + & + & + & + & + & + & + & + & + & + \\
\hline 24 & L. orientalis J. Ag. & + & + & + & + & & + & & + & + & + \\
\hline 25 & Amphiroa dilatata Lamx. & & & + & + & & + & & & + & + \\
\hline 26 & A. foliacea Lamouroux & & & + & + & & + & & & + & + \\
\hline 27 & $\begin{array}{l}\text { A. fragiliesima (L.) } \\
\text { Lamouroux }\end{array}$ & & & + & + & & & & & + & + \\
\hline 28 & $\begin{array}{l}\text { Cheilosporum spectabile } \\
\text { Harv. }\end{array}$ & & & + & & & & + & & + & + \\
\hline 29 & Jania adhaerens Lamx. & + & & & + & + & + & & & + & + \\
\hline 30 & J. capilacea Harvey & + & & & & & & & & + & + \\
\hline 31 & J. rubens (L.) Lamouroux & & & & & + & & & & & \\
\hline 32 & $\begin{array}{l}\text { J. ungulata Yendo f. } \\
\text { brevior Yendo }\end{array}$ & + & & & + & + & & & & + & + \\
\hline 33 & $\begin{array}{l}\text { Lithophyllum okamurae } \\
\text { Foslie }\end{array}$ & & & & + & + & & & & & + \\
\hline
\end{tabular}




\begin{tabular}{|c|c|c|c|c|c|c|c|c|c|c|c|}
\hline 34 & $\begin{array}{l}\text { L. pygrnaeurri (Heydrich) } \\
\text { Heydrich }\end{array}$ & & & & + & + & & & & & + \\
\hline 35 & $\begin{array}{l}\text { Mastophora pacifica } \\
\text { (Heydrich) Fosl. }\end{array}$ & + & + & & + & + & + & + & & + & + \\
\hline 36 & M. rosea (c. Ag.) Setch. & + & & & + & + & + & & & + & + \\
\hline 37 & $\begin{array}{l}\text { Mesophyllum erubescens } \\
\text { (Foslie) Lemoine }\end{array}$ & + & & + & & + & + & + & + & + & + \\
\hline 38 & $\begin{array}{l}\text { Gelidiella acerosa (Forsk.) } \\
\text { Feldm. et Ham. }\end{array}$ & + & & + & & & + & & & + & \\
\hline 39 & $\begin{array}{l}\text { G. lubrica (Kuetz.) Feldm. } \\
\text { et Ham. }\end{array}$ & + & & & & & + & & & + & \\
\hline 40 & $\begin{array}{l}\text { Gelidium crinale (Turn.) } \\
\text { Lamx. }\end{array}$ & + & + & & & & & & & + & \\
\hline 41 & $\begin{array}{l}\text { G. pusillum (Stackh.) Le } \\
\text { Jolis }\end{array}$ & & + & & & & & & & & \\
\hline 42 & Pterocladia parva Dawson & & + & + & & & & & + & + & + \\
\hline 43 & $\begin{array}{l}\text { Wurdemannia miniata } \\
\text { (Lmk.et Dc.) Feldm. et } \\
\text { Ham. }\end{array}$ & & & + & & + & & & + & + & + \\
\hline 44 & $\begin{array}{l}\text { Asparagopsis taxiformis } \\
\text { (Delile) Trevisan }\end{array}$ & & & + & & & & & & + & \\
\hline 45 & $\begin{array}{l}\text { Halymenia dilatata } \\
\text { Zanardini }\end{array}$ & + & & + & + & & + & + & + & + & + \\
\hline 46 & H. maculata J. Ag. & & & + & + & & + & + & + & & + \\
\hline 47 & Hypnea charoides Lamx. & + & & + & + & + & + & + & + & + & + \\
\hline 48 & H. boergesenii Tanaka & & + & + & + & + & & + & + & + & + \\
\hline 49 & H. esperi Borv & & & & & & & + & + & & \\
\hline 50 & H. pannosa J. Ag. & & & + & & & & + & + & + & + \\
\hline 51 & H. cornuta (Lamx.) J. Ag. & & & + & + & + & & + & + & + & + \\
\hline 52 & $\begin{array}{l}\text { Kappaphycus cottonii (W.v. } \\
\text { Bosse) Doty }\end{array}$ & + & & & + & & + & + & & + & + \\
\hline 53 & $\begin{array}{l}\text { Gracilaria arcuata } \\
\text { Zanardini }\end{array}$ & & & & + & & & & + & + & + \\
\hline 54 & G. eucheumoides Harvev & & + & & + & & & & & + & + \\
\hline
\end{tabular}




\begin{tabular}{|c|c|c|c|c|c|c|c|c|c|c|c|}
\hline 55 & $\begin{array}{l}\text { G. salicornia (C. Ag.) } \\
\text { Dawson }\end{array}$ & & & & + & & & & & + & \\
\hline 56 & $\begin{array}{l}\text { Champia parvula (C. Ag.) } \\
\text { Harv. }\end{array}$ & + & & & & & & & & + & + \\
\hline 57 & C. salicornioides Harvev & + & & & & & & & & + & + \\
\hline 58 & $\begin{array}{l}\text { Ceratodictyon spongiosum } \\
\text { Zan. }\end{array}$ & + & + & + & & + & + & + & + & & + \\
\hline 59 & $\begin{array}{l}\text { Gelidiopsis uracilie } \\
\text { (Kuetz.) Vickers }\end{array}$ & & & & & & + & & & + & \\
\hline 60 & $\begin{array}{l}\text { Rhodymenia anastomosans } \\
\text { W. V. Bosse }\end{array}$ & & + & & + & + & & + & + & + & + \\
\hline 61 & $\begin{array}{l}\text { Aglaothamnion neglectum. } \\
\text { Feldm. - Mazoyer }\end{array}$ & & & & + & + & & + & + & & + \\
\hline 62 & $\begin{array}{l}\text { Antithamnion basiporum. } \\
\text { Tokida et Inaba }\end{array}$ & & & & + & + & & & + & & + \\
\hline 63 & $\begin{array}{l}\text { Centroceras claoulatuni } \\
\text { (.C. Ag.) Mont. }\end{array}$ & & & & & & & & + & + & + \\
\hline 64 & $\begin{array}{l}\text { Ceramium cingulatum } \mathrm{W} \text {. } \\
\text { v. Bosse }\end{array}$ & & & & & & + & & + & + & + \\
\hline 65 & $\begin{array}{l}\text { C. clarionense Setch. et } \\
\text { Gardner }\end{array}$ & & & & & & + & & + & + & + \\
\hline 66 & $\begin{array}{l}\text { C. gracillimuni (Kuetz.) } \\
\text { Griffith et Harv. }\end{array}$ & & & & & & + & & & + & + \\
\hline 67 & C. mazatlanense Dawson & & & & & & + & & & + & + \\
\hline 68 & $\begin{array}{l}\text { Wrangelia argus (Mont.) } \\
\text { Mont. }\end{array}$ & + & & + & + & + & + & & & + & \\
\hline 69 & $\begin{array}{l}\text { Taenioma perpusillum. (J. } \\
\text { Ag.) J. Ag. }\end{array}$ & & & + & + & + & & & & + & \\
\hline 70 & Acrocystis nana Zanardini & & & & + & + & & & & + & + \\
\hline 71 & Bostrychia binderi Harv. & & & + & + & + & + & & & + & + \\
\hline 72 & $\begin{array}{l}\text { Bryocladia ceruicornis } \\
\text { (Kuetz.) Schmitz }\end{array}$ & & & + & & & & + & & + & + \\
\hline 73 & $\begin{array}{l}\text { Chondria armaia (Kuetz.) } \\
\text { Okam. }\end{array}$ & & + & + & & & + & + & & + & + \\
\hline 74 & Herposiphonia tenella $(\mathrm{C}$. & + & + & & & & & + & & + & + \\
\hline
\end{tabular}




\begin{tabular}{|c|c|c|c|c|c|c|c|c|c|c|c|}
\hline & Ag.) Ambronn & & & & & & & & & & \\
\hline 75 & $\begin{array}{l}\text { Lophosiphonia oillum } \\
\text { (J.Ag.) Setch et Gardner }\end{array}$ & + & + & & + & & & + & + & + & + \\
\hline 76 & $\begin{array}{l}\text { Laurencia cartilaginea } \\
\text { Yamada }\end{array}$ & + & + & + & + & & + & + & + & + & + \\
\hline 77 & L. corymbosa J. Ag. & + & & & & & + & & & + & + \\
\hline 78 & $\begin{array}{l}\text { L. papillosa (C. Ag.) } \\
\text { Greville }\end{array}$ & & & + & & & & & & + & + \\
\hline 79 & L. parvipapillata Tseng & & + & & + & & & + & & + & + \\
\hline 80 & $\begin{array}{l}\text { Melanamansia glomerata } \\
\text { (C. Ag.) Norris }\end{array}$ & + & & & + & & & & & + & + \\
\hline 81 & $\begin{array}{l}\text { Polysiphonia harlandii } \\
\text { Harvey }\end{array}$ & + & & & & + & + & & & + & + \\
\hline 82 & P. scopulorum Harvey & & & & & & + & & & + & + \\
\hline 83 & P. subtilissima Mont. & & & & & & + & & & + & + \\
\hline \multirow[t]{2}{*}{84} & $\begin{array}{l}\text { Tolypiocladia glomerulata } \\
\text { (C. Ag.) Schm. }\end{array}$ & & + & + & & & + & + & + & + & + \\
\hline & Phaeophyta & & & & & & & & & & \\
\hline 85 & $\begin{array}{l}\text { Feldmannia irregularis } \\
\text { (Kuetz.) Ham. }\end{array}$ & + & & + & + & + & + & + & + & + & + \\
\hline 86 & $\begin{array}{l}\text { Sphacelaria diuaricata } \\
\text { Mont. }\end{array}$ & & & + & + & + & + & + & + & + & + \\
\hline 87 & S. tribuloides Meneghini & & & + & + & & & + & & + & + \\
\hline 88 & $\begin{array}{l}\text { Dictyota bartayresii } \\
\text { Lamouroux }\end{array}$ & & + & & + & & + & + & & + & + \\
\hline 89 & $\begin{array}{l}\text { D. dichotoma (Huds.) } \\
\text { Lamouroux }\end{array}$ & & + & & + & & + & + & & + & + \\
\hline 90 & D. divaricata Lamx. & & + & & & & + & + & & + & + \\
\hline 91 & $\begin{array}{l}\text { Spathoglossum } \\
\text { vietnamense Phamh. }\end{array}$ & & & + & & + & + & + & + & & + \\
\hline 92 & Padina australis Hauck. & + & + & + & & + & & & + & + & + \\
\hline 93 & P. boryana Thivy & + & + & & & + & & & + & + & + \\
\hline 94 & $\begin{array}{l}\text { Chnoospora implexa } \\
\text { Hering ex J. Ag. }\end{array}$ & + & + & & + & + & + & + & + & + & + \\
\hline
\end{tabular}




\begin{tabular}{|c|c|c|c|c|c|c|c|c|c|c|c|}
\hline 95 & $\begin{array}{l}\text { Hydroclathrus clathratus } \\
\text { (C. Ag.) Howe }\end{array}$ & + & + & & + & + & + & + & + & + & + \\
\hline 96 & $\begin{array}{l}\text { Colpomenia sinuosa } \\
\text { (Roth) Derbes et Sol. }\end{array}$ & + & & & + & + & + & & + & + & + \\
\hline 97 & $\begin{array}{l}\text { Hormophysa articulata } \\
\text { Kuetz. }\end{array}$ & + & & + & + & & & & + & + & + \\
\hline 98 & $\begin{array}{l}\text { Turbinaria conoides (J. } \\
\text { Ag.) Kuetz. }\end{array}$ & + & + & + & + & & & & & + & + \\
\hline 99 & T. decurrens Bory & & + & & + & & & & & + & + \\
\hline 100 & T. ornata (Turn.) J. Az. & & + & + & + & & & & & + & + \\
\hline 101 & $\begin{array}{l}\text { Saraassum berberifolium } \\
\text { J. Ag. }\end{array}$ & + & + & + & + & + & + & + & + & + & + \\
\hline 102 & S. crassifolium J. Ag. & + & + & + & + & + & + & + & + & & + \\
\hline 103 & S. duplicatum J. Ag. & + & + & + & + & + & + & + & + & & + \\
\hline 104 & $\begin{array}{l}\text { S. henslowianum C. Ag. } \\
\text { ex. J. Ag. }\end{array}$ & + & + & + & + & + & + & + & + & & + \\
\hline 105 & S. oligocystum Mont. & + & + & + & + & + & + & + & + & + & + \\
\hline \multirow[t]{2}{*}{106} & S. polycystum. C. Ag. & + & + & + & + & + & + & + & + & & + \\
\hline & Chlorophyta & & & & & & & & & & \\
\hline 107 & $\begin{array}{l}\text { Enteromorpha clathrata } \\
\text { (Roth.) Grev. }\end{array}$ & + & & + & + & + & + & + & & + & \\
\hline 108 & E. kylinii Bliding & + & & + & & & & & & + & \\
\hline 109 & Ulva lactuca Linnaeus & & + & + & & & & & & + & \\
\hline 110 & U. papenfussii Phamh. & & + & & & & & & & + & \\
\hline 111 & U. reticulata Forsk. & & + & + & & & & & & + & \\
\hline 112 & $\begin{array}{l}\text { Anadyomene plicata } \mathrm{C} \text {. } \\
\text { Ag. }\end{array}$ & & & & & & & + & & + & + \\
\hline 113 & $\begin{array}{l}\text { Chaetomorpha crassa } \\
\text { (C. Ag.) Kuetz. }\end{array}$ & + & + & + & & + & & & & + & \\
\hline 114 & $\begin{array}{l}\text { Cladophora albida } \\
\text { (Huds.) Kuetz. }\end{array}$ & & + & + & + & + & & & & + & \\
\hline 115 & C. inserta Dickie & & + & & + & & & & & + & \\
\hline 116 & C. rugulosa Martens & & & & + & + & & & & + & \\
\hline
\end{tabular}




\begin{tabular}{|c|c|c|c|c|c|c|c|c|c|c|c|}
\hline 117 & $\begin{array}{l}\text { Rhizoclonium kochianum } \\
\text { Kuetz. }\end{array}$ & + & + & & + & + & & & + & + & + \\
\hline 118 & $\begin{array}{l}\text { Boodlea composita (Hary) } \\
\text { Brand. }\end{array}$ & + & & & + & + & & & + & + & \\
\hline 119 & $\begin{array}{l}\text { Boergesenia forbesii } \\
\text { (Harv.) Feldm. }\end{array}$ & & & & + & & + & & + & + & \\
\hline 120 & $\begin{array}{l}\text { Struvea anastomosans } \\
\text { (Harv.) Piccone }\end{array}$ & + & & + & + & & + & & + & + & + \\
\hline 121 & $\begin{array}{l}\text { Valonia fastigiata Harv. } \\
\text { ex. J. Ag. }\end{array}$ & + & & + & & & + & + & + & + & + \\
\hline 122 & $\begin{array}{l}\text { Dictyosphaeria verluysii } \mathrm{W} \text {. } \\
\text { v. Bosse }\end{array}$ & + & + & + & & + & + & + & + & + & + \\
\hline 123 & $\begin{array}{l}\text { Bornetella sphaeria (Zan.) } \\
\text { Solms-Laubach }\end{array}$ & + & + & + & & + & + & + & + & + & + \\
\hline 124 & Neomeris annulata Dickie & + & + & + & + & + & + & + & + & + & + \\
\hline 125 & $\begin{array}{l}\text { Acetabularia parvula } \\
\text { Solms-Laubach }\end{array}$ & + & + & + & + & + & + & & + & + & + \\
\hline 126 & Bryopsis pennata Lamx. & + & & + & + & + & & & + & + & + \\
\hline 127 & Codium arabicum Kuetz. & + & & + & + & & & & + & + & + \\
\hline 128 & Halimeda cuneata Barton & + & & + & + & & & + & + & + & + \\
\hline 129 & H. opuntia (L.) lamx. & + & & & & & & + & + & + & + \\
\hline 130 & Caulerpa leniilifera J. Ag. & + & & + & & + & + & & + & + & + \\
\hline 131 & C. racemosa (Forsk.) J. Ag. & & + & & & & + & & + & + & + \\
\hline 132 & C. serrulata (Forsk.) J. Ag. & + & & & + & & + & & + & + & \\
\hline 133 & C. taxifolia (Vahl) J. Ag. & + & & & + & + & + & & + & + & \\
\hline \multicolumn{2}{|c|}{ Tổng số: 133 loài } & 69 & 56 & 68 & 71 & 62 & 64 & 54 & 64 & 119 & 99 \\
\hline
\end{tabular}

\section{Phân bố}

\subsection{Phân bố rộng}

Qua bảng 1 ta thấy rằng số lượng loài tại các mặt cắt I đến VIII dao động trong khoảng 54 loài/mặt cắt (mặt cắt VIII) đến 71 loài (mặt cắt IV) và trung bình là 63 loài/mặt cắt. Số lượng loài giữa các mặt cắt có sự khác nhau không lớn vì cả hai đảo (Lý Sơn và An Bình) đều là đảo nhỏ, có nền đáy giống nhau và tương đối thuận lợi cho sự tồn tại và phát 
triển của các loài rong biển. Các điều kiện khác (dòng chảy, độ muối) cũng không có sự sai khác lớn.

Hệ số tương đồng Sorenson tại các mặt cắt dao động từ 0,46 (giữa mặt cắt II và VII, giữa II và VIII) đến 0,64 (giữa mặt cắt IV và $\mathrm{V}$ ) và trung bình là 0,56 (bảng 2)

Bảng 2: Hệ số tương đồng của rong biển tại các địa điểm nghiên cứu vùng quần đảo Lý Sơn

\begin{tabular}{|l|c|c|c|c|c|c|c|c|}
\hline & MC1 & MC2 & MC3 & MC4 & MC5 & MC6 & MC7 & MC8 \\
\hline MC8 & 0,63 & 0,46 & 0,59 & 0,60 & 0,57 & 0,62 & 0,61 & \\
\hline MC7 & 0,53 & 0,54 & 0,59 & 0,56 & 0,53 & 0,59 & & \\
\hline MC6 & 0,61 & 0,46 & 0,53 & 0,57 & 0,50 & & & \\
\hline MC5 & 0,66 & 0,47 & 0,52 & 0,64 & & & & \\
\hline MC4 & 0,60 & 0,50 & 0,57 & & & & & \\
\hline MC3 & 0,62 & 0,48 & & & & & & \\
\hline MC2 & 0,51 & & & & & & & \\
\hline MC1 & & & & & & & & \\
\hline
\end{tabular}

Hệ số tương đồng giữa mặt cắt II và VII, giữa II và VIII là nhỏ nhất do điều kiện (đặc biệt là chất đáy) ở hai mặt cắt này tương đối đồng nhất với nền đáy là đá gốc và rạn san hô (phần lớn là san hô chết). Tương tự, hệ số tương đồng giữa mặt cắt IV và $\mathrm{V}$ là lớn nhất vì có các điều kiện tương đối giống nhau.

\subsection{Phân bố sâu}

Từ kết quả của bảng 1 , chúng ta thấy rằng trong số 133 loài rong biển đã phát hiện được ở quần đảo Lý Sơn, có tới 119 loài phân bố ở vùng triều và 99 loài phân bố ở vùng dưới triều (trong đó có 83 loài phân bố ở cả vùng triều và dưới triều). Nhìn chung, các loài rong biển vùng nghiên cứu chủ yếu phân bố từ vùng triều giữa xuống đến độ sâu khoảng $5 \mathrm{~m}$ so với $0 \mathrm{~m}$ hải đồ. Đây là một yếu tố rất thuận lợi cho việc khai thác nhưng sẽ không thuận lợi cho việc tồn tại và phát triển của rong biển khi có gió mùa với sóng cùng hướng có cường độ mạnh. Khi sóng lớn, các loài phân bố ở vùng triều và phần trên của vùng dưới triều dễ bị tàn phá bởi sóng lớn và nhiệt độ cao (mùa hè). 


\section{3. Đặc trưng khu hệ}

Áp dụng tỷ số Cheney để tính toán đặc trưng khu hệ rong biển cho vùng nghiên cứu ta thấy rằng, tỷ lệ giữa tổng số loài Rong đỏ và Rong lục chia cho số loài Rong nâu là (71 + 21)/22 = 4,5, lớn hơn 3. Như vậy, khu hệ rong biển vùng quần đảo Lý Sơn mang tính nhiệt đới.

\section{KẾT LUẬN}

- Trong vùng ven bờ quần đảo Lý Sơn, chúng tôi đã xác định được 133 loài rong biển. Trong đó, rong Lam (Cyanophyta) có 13 loài, chiếm 9,8\% tổng số loài; rong Đỏ (Rhodophyta) - 71 loài, 53,4\%; rong Nâu (Phaeophyta) - 22 loài, 16,6\% và rong Lục (Chlorophyta) - 27 loài, 20,3\%.

- Số lượng loài tại các mặt cắt I đến VIII dao động trong khoảng 54 loài/mặt cắt (mặt cắt VIII) đến 71 loài (mặt cắt $\mathrm{IV}$ ) và trung bình là 63 loài/mặt cắt. Hệ số tương đồng Sorenson tại các mặt cắt dao động từ 0,46 (giữa mặt cắt II và VII, giữa II và VIII) đến 0,64 (giữa mặt cắt $\mathrm{IV}$ và $\mathrm{V}$ ) và trung bình là 0,56 .

- Về phân bố sâu, trong số 133 loài rong biển đã phát hiện được, có tới 119 lượt loài phân bố ở vùng triều và 99 lượt loài phân bố ở vùng dưới triều (trong đó có 83 loài phân bố ở cả vùng triều và dưới triều ). Phần lớn các loài phân bố từ vùng triều giữa xuống đến độ sâu khoảng $5 \mathrm{~m}$ so với $0 \mathrm{~m}$ hải đồ.

- Khu hệ rong biển vùng quần đảo Lý Sơn mang tính nhiệt đới với chỉ số $\mathrm{C}=4,5$.

\section{TÀI LIỆU THAM KHẢO}

1. Nguyễn Hưu Dinh, Huỳnh Quang Năng, Trần Ngọc Bút, Nguyễn Văn Tiến, 1993. Rong biển Việt Nam (phần phía Bắc). NXB. Khoa học-Kỹ thuật, Hà Nội. 364 tr.

2. Nguyễn Hũu Đại, 1997. Rong Mơ (Sargassaceae) Việt Nam: nguồn lợi và sử dụng. NXB. Nông nghiệp Tp Hồ Chí Minh, 199 tr.

3. Nguyễn Hũu Đại, Phạm Hũu Trí, 2001. Nguồn lợi rong biển đảo Lý Sơn. Tuyển tập Nghiên cứu Biển, tập XI. NXB. KH-KT, Hà Nội. Tr. 121-134. (159 loài).

4. Phạm Hoàng Hộ, 1969. Rong biển Việt Nam (phần phía Nam). Trung tâm học liệu, Sài Gòn, 558 tr. 
5. Võ Xuân Mai, Hoàng Công Tín, Lê Như Hậu, Bùi Minh Lý, Trần Quang Thái, Võ Thành Trung, Ngô Thanh Trúc, Vũ Thị Mo, 2010. Úng dụng công nghệ GIS và viễn thám trong xây dựng bản đồ vùng phân bố rong biển ở đảo Lý Sơn, tỉnh Quảng Ngãi. Hội nghị Khoa học kỷ niệm 35 năm Viện Khoa học và Công nghệ Việt Nam (Tiểu ban: Khoa học và Công nghệ biển), Hà Nội. Tr. 248-254.

6. Uỷ ban Khoa học và Kỹ thuật Nhà nước, 1981. Quy phạm tạm thời điều tra tổng hợp biển. Nxb. KH-KT, Hà Nội.

7. English S., C. Wilkinson, V. Baker, 1997. Survey Manual for Tropical Marine Resources. $2^{\text {nd }}$ Edition. H. P. Australian Institute of Marine Science, 390 p.

8. Cheney P., 1977. $(\mathrm{R}+\mathrm{C} / \mathrm{p})$ - A New and Improved Ratio for Comparing Seaweed Flores. J. Playral. 13 No. 2 supl. 12.

\title{
SPECIES COMPOSITION AND DISTRIBUTION OF SEAWEEDS AT LY SON ARCHIPELAGO, QUANG NGAI PROVINCE, VIETNAM
}

\section{DAM DUC TIEN, LE VAN SON, VU THANH CA}

\begin{abstract}
Summary: Ly Son is an archipelago with two islands - Ly Son and An Binh which are belonging to Quang Ngai province in Central Vietnam. Until now, there have been few studies on seaweeds at Ly Son.

This article presents results of two field surveys, conducted in November, 2009 and May, 2010 under the research project "Surveying and assessing status of ecosystems, collecting scientific data for the proposal of marine protected area and serving as tousism purposes at the near-shore of Ly Son archipelago". It was found that at the Ly Son archipelago, totally 133 seaweed species have been recorded. Among them, 13 species are Cyanophytes, 71 species are Rhdophytes, 22 species are Phaeophytes, and 21 species are Chlorophytes.

Among them, 119/133 species were collected in the littoral zone, 99 species in sublittoral zone and the most of them distributed in 0-5 water depth of subtidal zone. The marine algal flora in Ly Son archipelago is represented by tropical elements by Cheney index (1977).

Number of species at surveyed transects I to VIII varies from 54 species/transect of transect VIII) to 71 species (transect IV) and in average 63 species/transect. Sorrenson similar ratio varies from 0.46 (between transects II and VII, between II and VIII) to 0.64 (transects $I V$ and $V$ ) and in average 0,56. Seaweed at Ly Son are tropical seaweed with the ratio $C=4.5$.
\end{abstract}

Ngày nhận bài: 20 - 3 - 2011

Ngưòi nhận xét: PGS. TS. Nguyễn Chu Hồi 